\title{
ON THE OSCILLATION OF SECOND ORDER NONLINEAR DIFFERENCE EQUATIONS
}

\author{
RaVi. P. AgARWAL AND PATRICIA J. Y. WONG
}

\begin{abstract}
We shall discuss two powerful techniques, namely, the averaging method, and the inequalities method, which have been used for quite some time to establish the oscillations of second order differential equations, whereas their use in the study of difference equations is recent and deserves more attention.
\end{abstract}

Mathematics subject classification (1991): 39A10.

Key words and phrases: Oscillatory solutions, differential equations, difference equations, averaging method, inequalities method.

\section{REFERENCES}

[1] R. P. Agarwal, Difference Equations and Inequalities, Marcel Dekker, New York, 1992.

[2] G. J. ButLER, Integral averages and the oscillation of second order ordinary differential equations, SIAM J. Math. Anal. 11 (1980), 190-200.

[3] W. J. COLES, An oscillation criterion for second-order linear differential equations, Proc. Amer. Math. Soc. 19 (1968), 755-759.

[4] W. J. Coles AND D. Willett, Summability criteria for oscillation of second order linear differential equations, Ann. Mat. Pura Appl. 79 (1968), 391-398.

[5] L. H. ERBE AND P. YAN, Weighted averaging technique in oscillation theory foe second order difference equations, Canad. Math. Bull. 35 (1992), 61-69.

[6] J. R. GRAEF AND P. W. SPIKES, On the oscillatory behaviour of solutions of second order non-linear differential equations, Czech. Math. J. 36 (1986), 275-284.

[7] P. Hartman, On non-oscillatory linear differential equations of second order, Amer. J. Math. 74 (1952), 389-400.

[8] Ordinary Differential Equations, Wiley, New York, 1964.

[9] On nonoscillatory linear differential equations of second order, Proc. Amer. Math. Soc. 64 (1977), 251-259.

[10] I. V. KAMENEV, Some specifically nonlinear oscillation theorems, Mat. Zametki 10 (19 71), 129-134 (English translation: Math. Notes 10 (1971), 502-505).

[11] An integral criterion for oscillation of linear differential equations of second order, Mat. Zametki 23 (1978), 249-251, (English translation: Math. Notes 23 (1978), 136-138).

[12] M. K. KWONG AND J. S. W. WONG, Linearization of second-order nonlinear oscillation theorems, Trans. Amer. Math. Soc. 279 (1983), 705-722.

[13] _ An application of integral inequality to second order non-linear oscillation, J. Differential Equations 46 (1992), 63-77.

[14] M. NAITO, Integral averaging techniques for the oscillation and nonoscillation of solutions of second order ordinary differential equations, Hiroshima Math. J. 24 (1994), 657-670.

[15] C. G. PHILOS, On second order sublinear oscillation, Aequationes Math. 27 (1984), 242-254.

[16] _ Integral averages and second order superlinear oscillation, Math. Nachr. 120 (1985), 127-138.

[17] Oscillation criteria for second order superlinear differential equations, Canad. J. Math. 41 (1989), 321-340. 
[18] An oscillation criterion for superlinear differential equations of second order, J. Math. Anal. Appl. 148 (1990), 306-316.

[19] - Integral averages and oscillation of second order sublinear differential equations, Differential and Integral Equations 4 (1991), 205-213.

[20] C. G. PHILOS AND I. K. PURNARAS, Oscillations in superlinear differential equations of second order, J. Math. Anal. Appl. 165 (1992), 1-11.

[21] C. G. Philos AND I. K. PURnARAS, On the oscillation of second order nonlinear differential equations, Archivum mathematicum 59 (1992), 260-271.

[22] E. ThandapAnI, I. GyÖRI AND B. S. LALLI, An application of discrete inequality to second order nonlinear oscillation, J. Math. Anal. Appl. 186 (1994), 200-208.

[23] E. THANDAPANI AND S. PANDIAN, On the oscillatory behaviour of solutions of second order nonlinear difference equations, Zeitschrift für Analysis und ihre Anwendungen 13 (1994), 347-358.

[24] E. Thandapani, M. Maria Susai Manuel AND R. P. AgarWaL, Oscillation and nonoscillation theorems for second order quasilinear difference equations, Facta Universitatis (Nis), Mathematics and Informatics 11 (1996), 49-65..

[25] D. WILlETT, On the oscillatory behavior of the solutions of second order linear differential equations, Ann. Polon. Math. 21 (1969), 175-194.

[26] A. WinTnER, A criterion of oscillatory stability, Quart. Appl. Math. 7 (1949), 115-117.

[27] F. H. WONG AND C. C. YEH, Oscillation criteria for second order superlinear differential equations, Math. Japonica 37 (1992), 573-584.

[28] J. S. WONG, On the second order nonlinear oscillations, Funk. Ekva. 11 (1968), 207-234.

[29] An oscillation criterion for second order nonlinear differential equations, Proc. Amer. Math. Soc. 98 (1986), 109-112.

[30] - A sublinear oscillation theorem, J. Math. Anal. Appl. 139 (1989), 408-412.

[31] An oscillation criterion for second order nonlinear differential equations with iterated integral averages, Differential and Integral Equations 6 (1993), 83-91.

[32] J. S. W. WONG AND C. C. YEH, An oscillation criterion for second order sublinear differential equations, J. Math. Anal. Appl. 171 (1992), 346-351.

[33] P. J. Y. WONG AND R. P. AGARWAL, Oscillatory behavior of solutions of certain second order nonlinear differential equations, J. Math. Anal. Appl. 198 (1996), 337-354.

[34] Summation averages and the oscillation of second order nonlinear difference equations, Mathl. Compul. Modelling 24 (9) (1996), 21-35.

[35] Oscillation theorems for certain second order nonlinear difference equations, J. Math. Anal. Appl. 204 (1996), 813-829.

[36] B. G. ZHANG AND G. D. CHEN, Oscillation of certain second order nonlinear difference equations, J. Math. Anal. Appl. 199 (1996), 827-841. 